\title{
A trajetória artística de Hélio Oiticica e uma leitura para a favela carioca através da obra do artista1,2
}

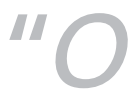

1. Resenha: Jacques, P. B. Estética da ginga: a arquitetura das favelas através da obra de Hélio Oiticica. Rio de Janeiro: casa da Palavra/ RIOARTE, 2001.

2. Este texto foi originalmente escrito para a disciplina Tópicos Especiais 3: Historiadores da cidade e do urbanismo, sob responsabilidade da Profa. Dra. Sarah Feldman e do Prof. Dr. Carlos Roberto Monteiro de Andrade. que era previamente considerado imutável é agora encarado como uma 'construção cultural', sujeita a variações tanto no tempo quanto no espaço" (Peter Burke, 1992).

Dois livros publicados nos últimos dez anos iluminam diferentes aspectos sobre a produção do artista plástico Hélio Oiticica: $A$ invenção de Hélio Oiticica, de Celso Favaretto (1992), e Estética da Ginga - a arquitetura das favelas através da obra de Hélio Oiticica (2001), de Paola Jacques.

Favaretto nos oferece uma narrativa da produção de Hélio Oiticica, desde seu princípio, com o grupo Frente no Rio de Janeiro (1954), até suas últimas proposições, em 1980, ano em que o artista falece. ${ }^{3}$ A perspectiva de Favaretto é narrar o modo didático como se dá a produção de Oiticica, valorizando-o como artista de vanguarda, ancorado numa produção teórica constante e cujos trabalhos parecem sempre conter latentes as proposições seguintes. A primeira edição de A invenção de Hélio Oiticica se deu no ano em que acontece a retrospectiva da produção do artista (1992) em Roterdã, Paris, Barcelona, Lisboa e Minneapolis, e que não foi exibida no Brasil. O texto, bastante objetivo, informa quem quer que seja o leitor sobre a trajetória de Hélio Oiticica. O primeiro capítulo, "A organização do delírio", é apropriação da expressão cunhada por Haroldo de Campos, em entrevista à Folha de S. Paulo, em 26 de julho de 1987, na qual se referia à capacidade do artista de ser inventivo e lúdico e ao mesmo tempo metódico e rigoroso.

Nos seis capítulos do livro - "A organização do delírio"; "Margens do programa"; "Das invenções

\section{Sara Cristiane Jara Grubert}

Arquiteta, mestranda do Programa de Pós-graduação do Departamento de Arquitetura da Escola de Engenharia de São Carlos, Universidade de São Paulo, Av. Comendador Alfredo Maffei, 1380 , ap. 12B, São Carlos, SP, CEP 13561-240, (16) 3374-9379, saragrubert@uol.com.br

à invenção"; "Programa ambiental"; "Além do ambiente"; e "Hélio, nos fios do experimental" -, Favaretto traça a trajetória do jovem e rigoroso artista até a formulação de "arte ambiental" e a conseqüente diluição da arte na vida. Com sua morte prematura, em 1980, Hélio Oiticica deixa em aberto qual seria a seqüência do limite com o qual se deparou, e que ainda hoje faz sentido nas discussões sobre arte: quais seriam (ou quais são) os encaminhamentos da arte após sua dessacralização, quando esta foi absorvida pelo viver ordinário? O livro de Favaretto tem por objeto de estudo a singularidade da experiência de Hélio Oiticica, a própria obra de arte e seus caminhos.

Numa perspectiva diversa, nas 160 páginas de Estética da Ginga, Paola Jacques nos oferece uma leitura da produção artística de Hélio Oiticica que se detém sobre seu diálogo com a arquitetura vernacular. A favela que a autora nos propõe não é antítese da metrópole, com suas arquiteturas gigantescas e fantásticas, mas um organismo vivo e perfeitamente inserido no espaço da cidade, apenas com uma dinâmica diferente. Sua reflexão parte de uma experiência pessoal, num encontro que parecia Ihe seguir ou esperar. Paola Jacques foi aluna da Faculdade de Arquitetura e Urbanismo da Universidade Federal do Rio de Janeiro, localizada no Campus Universitário da Ilha do Fundão, e a caminho da Universidade era necessário passar por uma parte da favela da Maré: este encontro entre a Academia e a Favela foi a semente para este estudo que toma o espaço construído das favelas como o negativo da arquitetura, a antiarquitetura por excelência. O segundo encontro com a favela, e que também norteou o trabalho, deu-se em Paris: mais especificamente na Galeria Nacional do Jeu 
de Paume, onde a autora teve contato com obras de Hélio Oiticica. Dali nasceu a idéia de "estética da ginga": nas proposições do artista estavam presentes fragmentos sensoriais da topografia da favela, suas cores. O andar descalço era, como descreveu Jacques, um pedaço do Rio de Janeiro no Jeu de Paume.

Tanto para o artista Hélio Oiticica quanto para o trabalho de Paola Jacques, o encontro com este Rio de Janeiro de estéticas múltiplas foi decisivo: no ano de 1964, quando começou a freqüentar a Escola de Samba Estação Primeira da Mangueira, Hélio Oiticica passou a viver no morro. É desta fase da produção do artista que parte Estética da Ginga, valorizando a concepção de "arte ambiental" de Oiticica, que segundo o artista é:

"a posição com referência a uma 'ambientação' e a conseqüente derrubada de todas as antigas modalidades de expressão: pintura-quadro, escultura, etc., propõe uma manifestação total, íntegra, do artista nas suas criações, que poderiam ser proposições para a participação do espectador" (Oiticica, 1986, p. 78).

Já na capa de Estética da Ginga as cores chamam a atenção do leitor para o universo singular tratado no texto: em verde e rosa, Hélio Oiticica aparece ensaiando o passo ao lado de Nininha da Mangueira. Há uma elegância na cena que anuncia o esforço do artista em adentrar a fundo em sua descoberta: a cidade. Na contracapa está a imagem do morro, que faz lembrar o "Parafuso", movimento em que o passista gira o corpo rapidamente lançando-se para o alto, apreendendo assim as imagens ao seu redor, numa rápida confusão dos sentidos. É assim a imagem da favela para seus não moradores: atordoante para a percepção.

A noção de cotidiano está presente de duas formas no trabalho de Jacques. Uma é inerente à própria experiência de Hélio Oiticica, que faz do ritual do carnaval parte de seu cotidiano - o esforço todo ao qual se submete, ensaiando com os passistas, passando a fazer parte do que se propunha desvendar e apresentar. A outra diz respeito à trajetória da própria autora: na exposição em Paris, na qual se deparou com obras de Hélio Oiticica, a ambientação deflagrou lembranças afetivas e sensoriais da Cidade Maravilhosa - donde a autora buscou perceber, apreender e decodificar o Rio de Janeiro e sua estética única. Entra em cena a morfologia da favela: a perpetuação sem o aspecto da permanência - um tempo não tempo, como também é a favela -, uma não arquitetura. O fio que conduz o texto é a abordagem estética e há uma discussão específica que associa a produção artística a uma pesquisa sobre o espaço da cidade. Ao negar a arquitetura como é estudada, a autora pede mais atenção às favelas e propõe um ponto de intersecção entre a arquitetura ensinada na academia e a arquitetura popular das favelas. A favela, embora não seja representativa do consenso médio sobre a cidade ideal, faz parte do movimento da existência e da própria construção citadina. A base teórica a conduzir o trabalho é a noção de movimento Deleuziana: "O movimento é uma translação no espaço" (Deleuze in Jacques, 2001, p. 149).

O uso das imagens da produção artística de Hélio Oiticica dialoga perfeitamente com as figuras conceituais usadas pela autora, pois, de fato, estas estão fortemente presentes nos trabalhos do artista. A própria noção do espectador de arte como participador, nas proposições de Oiticica, remete à favela, onde os moradores atuam constantemente na produção de seus barracões. As obras do artista a partir de seu encontro com a Mangueira configuram-se tal qual a favela: espaços-movimento. É esta idéia que liga as três figuras conceituais que dão título a três capítulos: "Fragmento", "Labirinto" e "Rizoma". Sendo a linha que os liga não necessariamente cronológica, o livro pode ser lido do fim para o começo sem prejuízo de compreensão, incluindo a introdução, que relaciona arquitetura das favelas/arquitetura das cidades planejadas e estética das favelas/figuras conceituais, e o texto final - Epílogo: espaço-movimento.

O "Fragmento" trata da repetição - o processo de montar e desmontar constante nas favelas. Para cada repetição tem-se uma montagem diferente. É no tempo que Paola Jacques encontra a chave para distinguir as duas arquiteturas com as quais se depara:

"A grande distinção entre a maneira de tratar o espaço dos favelados e dos arquitetos decorre também de sua relação com a temporalidade: 
conforme a idéia seja de abrigar ou de habitar, há um processo espaço-temporal diferente. Podemos dizer então que os arquitetos têm o hábito de espacializar o tempo, enquanto os favelados agem mais temporalizando o espaço" (Jacques, 2001, p. 55).

Nas favelas, os abrigos não são pré-projetados e quase nunca têm forma fixa. O "Fragmento" é a imagem temporal da repetição diferente, e o "Labirinto" é a escala urbana do fragmento. As noções de "Fragmento" e "Labirinto" estão, portanto, contidas uma na outra. Os registros que surgem do "Labirinto" são cartografias do tempo, e não do espaço. Diz Paola:

"A grande diferença entre o labirinto improvisado e as cidades modernas planejadas ex nihilo seria essa inversão da situação: em espaços labirínticos como os que vimos - a partir do espaço já dado todo e qualquer mapa só pode ser produzido a posteriori; no que concerne às grandes edificações urbanas, ocorre o contrário: os mapas existem antes das cidades, em planos e projetos. Vimos, através dos labirintos de Hélio Oiticica, que a experiência espacial pessoal e coletiva é primordial para constituir um labirinto e que é impossivel ter-se qualquer previsão (projeto) desta experiência sensorial e subjetiva do espaço. No entanto, a própria existência da disciplina urbanística tradicional, como estratégia, ainda é em grande parte orientada para a caça aos labirintos, ou seja, para a ordenação formal e racional do espaço urbano, de forma a impedir a experiência labiríntica" (Jacques, 2001, p. 97).

O "Rizoma", por sua vez, também carrega a idéia de movimento, cuja antítese é a árvore. O movimento é que transforma a configuração do espaço - a favela tem dinâmica própria -, e segundo a autora:

"A diferença, portanto, entre os territórios urbanos das cidades convencionais e as ocupações 'selvagens' dos terrenos pelas favelas é o caráter móvel das linhas de fuga, a desterritorialização. Oiticica nos mostrou, sobretudo com Barracão, o quanto essas linhas são sutis e profundamente ligadas à idéia de criação de uma comunidade. São as células
Figura 1: Hélio Oiticica na Mangueira, foto de Andreas Valentin. In: Jacques, P. B. Estética da ginga: a arquitetura das favelas através da obra de Hélio Oiticica. Rio de Janeiro: Casa da Palavra/ RIOARTE, 2001.

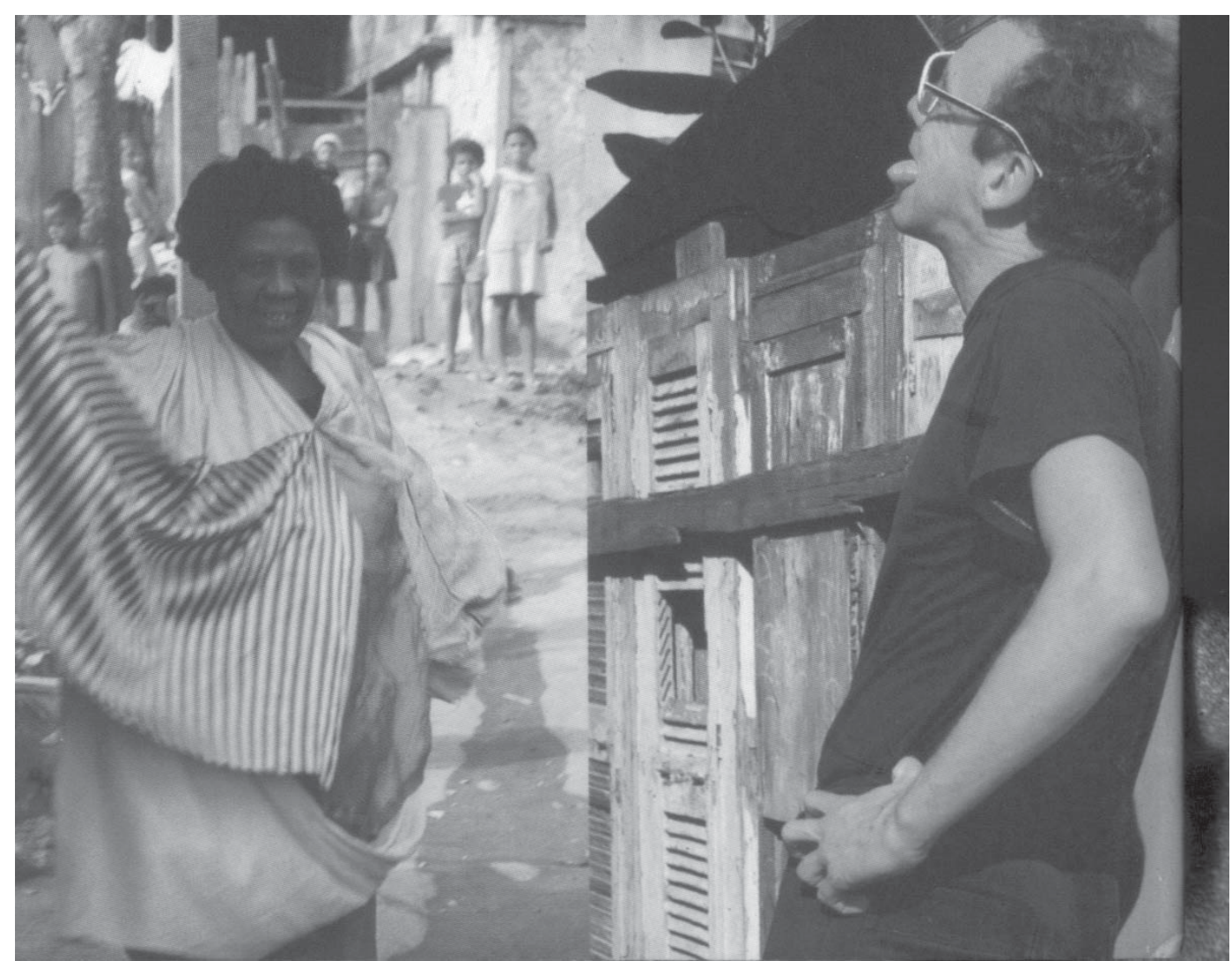


comunitárias (que brotam e se reproduzem) os verdadeiros vetores da abertura e do movimento (territorialização-desterritorialização). Por outro lado, toda a organização territorial não espontânea se baseia na demarcação fixa (e freqüentemente materializada), no fechamento e, em conseqüência, no cessar dos movimentos preexistentes" (Jacques, 2001, p. 142).

Para a autora, projetos oficiais que falam de "preservação das favelas" devem pensar antes a preservação de seu movimento. Sugere, então, o método dos "jardins em movimento", de Gilles Clément, propondo "bairros em movimento":

"Seria o caso de proceder através de quase nãointervenções, ou seja, de intervenções mínimas que seguissem os fluxos naturais e espontâneos, as linhas de fuga e as linhas de desterritorialização das favelas já existentes. Tratar-se-ia de passar à ação respeitando não somente o caráter rizomático, mas também labiríntico e fragmentário das favelas, ou seja, seguindo o processo e a estética das favelas iniciados pelos favelados, a despeito da lógica preconizada por arquitetos, urbanistas e planejadores em geral" (Jacques, 2201, p. 142).

Nascendo de uma experiência pessoal, acreditamos que ao lado das leituras interessantíssimas desvendadas por Paola Jacques para a obra de Hélio Oiticica, Estética da Ginga romantiza o olhar sobre a favela e sua arquitetura popular. Reaparece aqui a questão colocada por Burke (1992): a dificuldade de precisar "cultura popular", enquanto a cultura erudita não apresenta dificuldades para definição. O intuito do trabalho de Paola não é exaltar a antítese cidade erudita versus cidade popular, mas o de oferecer um denominador comum, onde ambas possam coexistir. Isto torna-se mais claro quando a autora lança a idéia do arquiteto-urbano como:

"aquele que trabalha nesses limites, trabalha com o entre, nesses espaços do entre, espaços sempre na beira, no limite. Estar entre não significa, aqui, estar isolado de um lado e de outro, mas sim estar ao mesmo tempo nos dois lados, na interseção.

(...) Ele também seria aquele que é sensível a todos os fluxos dos espaços-movimento, respeitando as mais diversas relações e diferenças possíveis, espaçotemporais e outras, e, conseqüentemente, valorizando a própria alteridade e diversidade na arquitetura urbana" (Jacques, 2001, p. 155).

Ainda que a proposta de conservação das favelas através dos "bairros em movimento" seja razoavelmente prudente, na medida em que parte da vontade de assumir a colaboração de todos na construção da cidade, fica a pergunta: onde ficam os conflitos de interesse?

\section{Referências bibliográficas}

BURKE, P. Abertura: a nova história, seu passado e seu futuro. p. 7-37. In: BURKE, P. (Org.). A escrita da história: novas perspectivas. 2. ed. São Paulo: UNESP, 1992.

JACQUES, P. B. Estética da ginga: a arquitetura das favelas através da obra de Hélio Oiticica. Rio de Janeiro: Casa da Palavra/RIOARTE, 2001.

FAVARETTO, C. F. A invenção de Hélio Oiticica. 2. ed. rev. São Paulo: EDUSP/FAPESP, 2000.

OITICICA, H. Aspiro ao grande labirinto. In: FIGUEIREDO, L.; PAPE, L.; SALOMÃO, W. (Orgs.). Seleção de textos. Rio de Janeiro: Rocco, 1986. 